\title{
The activation of Akt during preoperative chemotherapy for esophageal cancer correlates with poor prognosis
}

\author{
AKIKO YOSHIOKA, HIROSHI MIYATA, YUICHIRO DOKI, TAKUSHI YASUDA, MAKOTO YAMASAKI, \\ MASAAKI MOTOORI, KAZUYUKI OKADA, JIN MATSUYAMA, YOUICHI MAKARI, \\ ITSURO SOHMA, SHUJI TAKIGUCHI, YOSHIYUKI FUJIWARA and MORITO MONDEN
}

Department of Gastroenterological Surgery, Graduate School of Medicine, Osaka University, Osaka, Japan

Received November 2, 2007; Accepted December 23, 2007

\begin{abstract}
The activation of the PI3K/Akt/mTOR pathway plays an important role in tumorigenesis and resistance to anticancer drugs. The aim of this study was to elucidate the role of the Akt/mTOR pathway in chemoresistance and the prognosis of patients with esophageal squamous cell carcinoma (ESCC) who received preoperative chemotherapy. We evaluated p-Akt and p-mTOR expression by immunohistochemistry in the surgical specimens of 143 ESCC (51 patients with and 92 without preoperative chemotherapy). In 37 patients of the former group, paired tissue samples obtained before and after chemotherapy were examined immunohistochemically. The incidence of p-Akt expression was higher in ESCC with than without chemotherapy (51.0 vs. $25.0 \%$, $\mathrm{p}=0.0018$ ). Although $\mathrm{p}$-Akt expression was not associated with an advanced tumor stage, a comparison between before and after chemotherapy demonstrated an increased p-Akt expression during chemotherapy $(\mathrm{p}=0.0348)$. The $\mathrm{p}$-Akt expression did not correlate with survival in ESCC without chemotherapy, but was associated with poor prognosis in those with chemotherapy $(\mathrm{p}=0.0058)$. In particular, an increased p-Akt expression during chemotherapy was associated with poor survival $(\mathrm{p}=0.0022)$. Notably, the $\mathrm{p}$ mTOR expression did not correlate with p-Akt expression $(p=0.1482)$. The depth of the tumor invasion, clinical response and p-Akt expression correlated with the prognosis of 51 ESCC with chemotherapy. A multivariate analysis showed that p-Akt expression was the only independent predictor of poor prognosis in ESCC patients with chemotherapy. p-Akt expression increases after chemotherapy in ESCC and a high expression correlates with poor prognosis. Our results suggest that the activation of Akt is a potentially useful therapeutic target in ESCC patients treated with chemotherapy.
\end{abstract}

Correspondence to: Dr Hiroshi Miyata, Department of Gastroenterological Surgery, Graduate School of Medicine, Osaka University, 2-2 Yamadaoka, Suita, Osaka 565-0871, Japan

E-mail: hmiyata@surg2.med.osaka-u.ac.jp

Key words: esophageal squamous cell carcinoma, chemotherapy, $\mathrm{PI} 3 \mathrm{~K} / \mathrm{Akt} / \mathrm{mTOR}$ pathway, prognosis, serine/threonine kinase

\section{Introduction}

Esophageal cancer is one of the most intractable of the gastrointestinal cancers and prognosis remains poor even in those patients who undergo surgical resection (1). To improve the prognosis of esophageal cancer, preoperative chemotherapy followed by surgery is a frequently used and commonly accepted strategy for the management of advanced esophageal cancer. A number of previous studies reported that preoperative chemotherapy improved the survival of esophageal cancer patients who respond to chemotherapy, although the overall response was $30-40 \%$ and the prognosis of non-responders remained poor (2). Thus, it is necessary to overcome this chemoresistance through a better understanding of the molecular mechanism of chemoresistance.

Akt, a serine/threonine kinase, activated by extracellular stimuli in a phosphatidylinositol 3'-kinase (PI3k)-dependent manner, plays a pivotal role in oncogenesis (3). The Akt kinase family consists of three isoforms: Akt1, -2 and -3 , which are closely related to each other and share a high degree of amino acid sequence identity $(4,5)$. Studies have reported that the activation of the Akt kinase is frequently observed in a variety of cancers, including the breast, prostate, ovary and pancreas (6-10). Thus, activation of the Akt kinase may be associated with increased cell growth and proliferation. Akt has also been implicated in the resistance to apoptosis through multiple mechanisms (11). Akt is activated by phosphorylation at Ser473 and Thr308 downstream of PI3K. The activated Akt phosphorylates several key apoptotic proteins such as Bad, forkhead transcription factors and nuclear factor-к B (NF-кB) (12-15). In this regard, Akt directly and indirectly phosphorylates Bad, a bcl-2 homology domain 3 (BH-3)-containing protein, promoting its sequestration in the cytoplasm by 14-3-3 proteins and preventing the induction of Bad-mediated apoptosis $(11,13)$. The FoxO family of forkhead transcription factors, which enhances the transcription of several pro-apoptotic proteins such as the death-receptor Fasligand and Bim, is phosphorylated and inactivated by activated Akt signaling (12). In addition, Akt activation also enhances the NF- $\mathrm{kB}$-mediated transcription, probably by increasing the nuclear localization of NF- $\mathrm{kB}$ through the phosphorylation of the IкB kinase $(14,15)$.

The mammalian target of rapamycin (mTOR) is one of the kinase pathways downstream of the PI3K/Akt pathway 
and a key regulator of protein synthesis and cell growth, proliferation and viability. In response to mitogen stimulation, mTOR regulates the initiation of RNA translation through two distinct pathways: i) the phosphorylation and activation of ribosomal p70 S6 kinase (S6K1) (16), and, ii) the capdependent translation via the eukaryotic initiation factor $4 \mathrm{E}$ (elF4E) (17). Overexpression of eIF4E is observed in several types of cancers such as head and neck and gastrointestinal cancers $(18,19)$. These findings support the notion that activation of the Akt-mTOR pathway is oncogenic in several cancer types.

A number of in vitro studies have suggested that activation of the PI3K/Akt/mTOR pathway plays an important role in chemoresistance in cancer cells (20). However, the role of this pathway has not been elucidated in esophageal cancers. At present, several molecules, such as MLH1, MRP and ERCC1, are considered to be associated with chemoresistance in esophageal cancers (21-23), but the exact mechanism thereof remains unclear. The aims of the present study were: i) to evaluate immunohistochemically, the relationship between the Akt/mTOR expression and several clinicopathological parameters and the clinical outcome in patients with esophageal cancers treated with chemotherapy, and, ii) to investigate whether Akt-mTOR is a suitable therapeutic target in patients with esophageal squamous cell carcinoma (ESCC).

\section{Materials and methods}

Patients and samples. From 1999 to 2004, 195 patients with squamous cell carcinoma of the thoracic esophagus underwent curative resection at the Department of Gastroenterological Surgery, Osaka University Hospital. Of these patients, 51 underwent preoperative chemotherapy followed by surgery and 52 underwent preoperative chemoradiotherapy followed by surgery, while the remaining 92 underwent surgery without preoperative therapy. In our institution, patients with lymph node metastasis at the initial diagnosis are advised to undergo preoperative chemotherapy before surgery. The study subjects were the 51 patients with preoperative chemotherapy and 92 patients without preoperative therapy. The protocol of preoperative chemotherapy was: $70 \mathrm{mg} / \mathrm{m}^{2}$ cisplatin (CDDP), $35 \mathrm{mg} / \mathrm{m}^{2}$ adriamycin by intravenous infusion on day 1 and $700 \mathrm{mg} / \mathrm{m}^{2} 5$-fluorouracil by continuous intravenous infusion for $24 \mathrm{~h}$ on days $1-7$, every 4 weeks (22). Surgical resection was performed 4-6 weeks after completion of two courses of this treatment regimen. A resection of the thoracic esophagus and mediastinal lymph nodes was performed as standard procedure. Surgical specimens were fixed in $10 \%$ formaldehyde and routinely processed for paraffin embedding. Histological sections $(4 \mu \mathrm{m})$ were stained with hematoxylin and eosin (H\&E) and a representative section from each patient with the deepest tumor infiltration was subjected to immunohistochemistry. In 37 out of 51 patients with esophageal cancer who received preoperative chemotherapy, biopsy samples obtained before preoperative therapy were also subjected to immunohistochemistry.

The study protocol was approved by the Human ethics review committee of the Graduate School of Medicine, Osaka University and a signed consent form was obtained from each subject.
Follow-up. After hospital discharge, patients were seen every month for the first year and every 2 months thereafter. A computed tomography was performed every 4 months for the first year and every 6 months thereafter, and an upper gastrointestinal endoscopy was performed annually. All data were collected and entered prospectively into a database and updated at regular intervals. Complete follow-up information until death or May 2006 was available for all patients. The median follow-up period was 48 months (range, 18-89).

Evaluation of the response to chemotherapy. The clinical response to chemotherapy was evaluated by changes in primary tumor size on a computed tomography scan relative to its size before chemotherapy, based on RECIST criteria (24): complete response (CR) which represented the disappearance of the tumor, partial response (PR) representing at least a $30 \%$ decrease in the sum of the largest diameter, progressive disease (PD) which represented an increase of at least $20 \%$ in the sum of the largest diameter and stable disease (SD) which had insufficient shrinkage to qualify as PR and insufficient increase to qualify as PD.

The histopathological response to chemotherapy was evaluated by the proportion of viable cancer cells relative to whole cancer tissue on hematoxylin-eosin-stained sections of the surgical specimens according to the Japanese Society for Esophageal Diseases criteria (25): grade 0, no histological changes; grade 1a, viable cancer cells constituted more than two thirds of the tumor tissue; grade $1 \mathrm{~b}$, viable cancer cells constituted between one-third and two-thirds of the tumor tissue; grade 2, viable cancer cells constituted less than onethird of the tumor tissue and grade 3 , no residual viable cancer cells.

Immunohistological staining procedures and evaluation of the staining. Immunostaining for phospho-Akt (p-Akt) and phospho-mammalian target of rapamycin (p-mTOR) was performed using streptavidin-peroxidase complex methods as previously described (26). Paraffin sections $(4 \mu \mathrm{m})$ were deparaffinized and heated in $0.01 \mathrm{M}$ citrate buffer $(\mathrm{pH}$ 6.0) for $45 \mathrm{~min}$ at $95^{\circ} \mathrm{C}$. The endogenous peroxidase was blocked with $0.3 \% \mathrm{H}_{2} \mathrm{O}_{2}$ in methanol. The sections were then covered with $10 \%$ normal rabbit serum for $20 \mathrm{~min}$ at room temperature. These sections were incubated overnight at $4{ }^{\circ} \mathrm{C}$ with primary antibodies [p-Akt ser473, dilution 1:100 (Cell Signaling Technology, Beverly, MA) and p-mTOR Ser2448, dilution 1:50 (Cell Signaling)] and then processed by the biotinstreptavidin method using a commercially-available kit, according to the manufacturer's instructions (Histo-Fine SAB-PO kit, Nichirei, Japan). For negative controls, nonimmunized mouse or rabbit IgG serum (Vector Laboratories, Burlingame, CA) was used as the primary antibody, which yielded negative results. Color was developed with diaminobenzidine tetrahydrochloride supplemented with $0.02 \%$ hydrogen peroxide and the nuclei were counterstained with Meyer's hematoxylin. An antibody preincubated with antigen peptide was used for negative control tests, which yielded a uniformly negative result.

The immunoreactivities of $\mathrm{p}$-Akt and p-mTOR were evaluated according to the intensity and frequency of positively-stained cells. The staining intensity of each cancer 

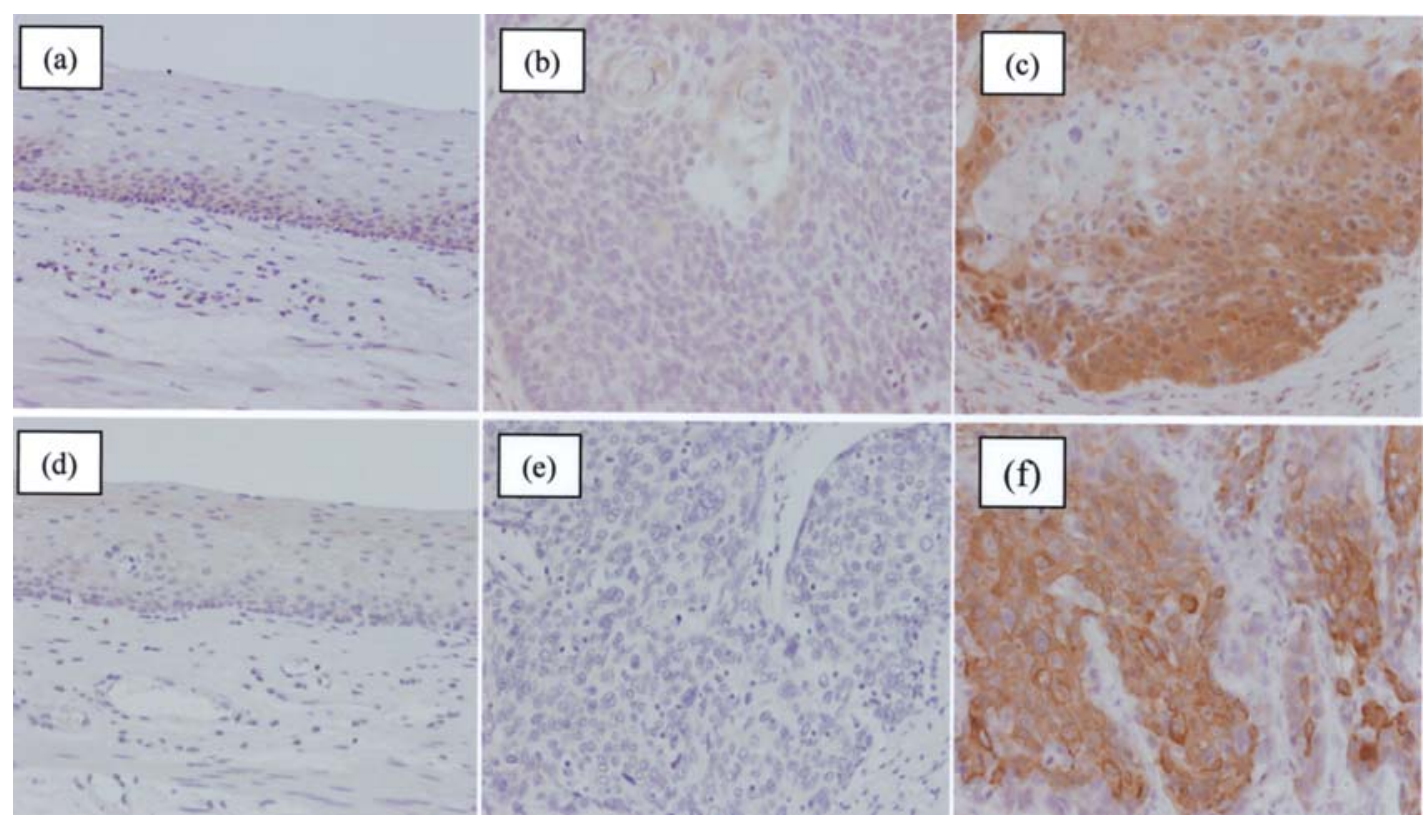

Figure 1. Immunohistochemical expression of phosphorylated-AKT (a-c) and -mammalian target of rapamycin (d-e). Phosphorylated-Akt expression in normal squamous epithelium (a). The immunoreactivity of phosphorylated-Akt in ESCC was classified as low (b) or high (c), according to the intensity and frequency of positively-stained cells. Phosphorylated-mTOR expression in normal squamous epithelium (d). The immunoreactivity of phosphorylated-mTOR in ESCC was also classified as low (e) or high (f), according to the intensity and frequency of positively-stained cells. Tumors containing $>50 \%$ positive tumor cells were classified as high expression and those with $\leq 50 \%$ positive tumor cells as low expression. Magnification, $\mathrm{x} 200$.

cell was classified as follows: equal to weaker intensity (negative) and stronger intensity (positive), relative to the normal epithelium. Tumors containing $>50 \%$ positive tumor cells were classified as high expression and those with $\leq 50 \%$ positive tumor cells as low expression. For confirmation, the immunohistochemical evaluation of p-Akt and p-mTOR was repeated twice by two pathologists (A. Y. and H. M.).

Statistical analysis. The association between the expression measured by immunohistochemistry and clinicopathological parameters was analyzed using the Mann-Whitney U, Spearman's rank correlation, or Fisher's exact test. Changes in p-Akt expression during chemotherapy were analyzed by the Wilcoxon single-rank test. Overall survival was calculated from the date of operation to the occurrence of the event or to the last known date of follow-up. Actual survival was calculated by the Kaplan-Meier and statistically evaluated by the log-rank test. The Cox proportional hazards regression model was used to analyze the simultaneous influence of prognostic factors. In all analyses, the p-value $<0.05$ was accepted as statistically significant. These analyses were carried out using StatView J5.0 software package (Abacus Concepts, Inc., Berkeley, CA).

\section{Results}

p-Akt and p-mTOR expression in the primary ESCC and normal mucosa without preoperative chemotherapy. We evaluated the expression of p-Akt and p-mTOR in 92 ESCC of patients who did not receive preoperative chemotherapy. p-Akt was not detected in the basal and parabasal layers of the normal stratified squamous epithelium, but was weakly stained in the granular and keratinizing layers (Fig. 1a).
ESCC cells expressing p-Akt showed positive staining mainly in the cytoplasm and sometimes in the nucleus, whereas the surrounding stromal cells showed little or no staining (Fig. 1c). To determine the status of mTOR activation downstream of Akt, we examined the phosphorylation status of mTOR using an antibody directed at the phosphorylated mTOR Ser2448, which recognizes the active form of the mTOR kinase (27). As with the p-Akt expression, the p-mTOR expression was found in the cytoplasm of ESCC cells, but not in the normal mucosa and stromal cells (Fig. 1d and f).

\section{Comparison of the p-Akt and p-mTOR expression between} ESCC treated with and without chemotherapy. There were no significant differences in the location of tumor, depth of tumor invasion and tumor differentiation, between patients who received chemotherapy and those who did not. However, a higher percentage of patients who received chemotherapy had lymph node metastasis at the initial diagnosis compared with those who did not (Table I). We then examined the expression of p-Akt and p-mTOR in the ESCC of patients who received chemotherapy prior to surgery. The incidence of p-Akt-positive ESCC among patients who received chemotherapy [26 out of $51(51.0 \%)$ ] was significantly $(\mathrm{p}=0.0018)$ higher than that among those who did not [23 out of $92(25.0 \%)]$. On the other hand, there was no significant difference in p-mTOR expression between ESCC of patients who received chemotherapy and those who did not $(\mathrm{p}=0.2090)$ (Table II). There was no significant correlation between the expression of p-Akt and p-mTOR in $92 \mathrm{ESCC}$ of the patients who did not receive chemotherapy (data not shown).

The high expression of $p$-Akt is associated with a poor prognosis in the ESCC patients who received chemotherapy. 
Table I. The clinicopathological features of 143 patients with esophageal cancer who did or did not receive preoperative chemotherapy.

\begin{tabular}{|c|c|c|c|}
\hline & $\begin{array}{c}\text { Untreated } \\
{[\%]}\end{array}$ & $\begin{array}{c}\text { Treated } \\
{[\%]}\end{array}$ & p-value \\
\hline Total no. & 92 cases & 51 cases & \\
\hline Age $($ mean \pm SEM $)$ & $63 \pm 8.2$ & $61 \pm 7.3$ & $0.1300^{c}$ \\
\hline \multicolumn{4}{|l|}{ Gender } \\
\hline Male & 85 [92] & $45[88]$ & \multirow[t]{2}{*}{0.5600} \\
\hline Female & $7[8]$ & $6[12]$ & \\
\hline \multicolumn{4}{|l|}{ Location of tumor } \\
\hline Upper thoracic & $9[10]$ & $7[14]$ & \multirow[t]{3}{*}{0.4550} \\
\hline Middle thoracic & $47[47]$ & 19 [37] & \\
\hline Lower thoracic & 36 [39] & 25 [49] & \\
\hline \multicolumn{4}{|c|}{ Depth of tumor invasion ${ }^{a}$} \\
\hline $\mathrm{cT} 1+2$ & $43[47]$ & $16[30]$ & \multirow[t]{2}{*}{$0.0738^{\circ}$} \\
\hline $\mathrm{cT} 3+4$ & $49[53]$ & $35[70]$ & \\
\hline \multicolumn{4}{|c|}{ Lymph node metastasis ${ }^{\mathrm{a}}$} \\
\hline $\mathrm{cNO}$ & $42[46]$ & $3[6]$ & \multirow[t]{2}{*}{$<0.0001$} \\
\hline $\mathrm{cN} 1$ & $50[54]$ & 48 [94] & \\
\hline \multicolumn{4}{|c|}{ Histological differentiation ${ }^{b}$} \\
\hline Well SCC & $24[26]$ & $13[26]$ & \multirow[t]{3}{*}{$0.4454^{\mathrm{C}}$} \\
\hline Mod SCC & $46[50]$ & $21[41]$ & \\
\hline Poor SCC & $22[24]$ & $17[33]$ & \\
\hline \multicolumn{4}{|l|}{ Clinical stage ${ }^{\mathrm{a}}$} \\
\hline $\mathrm{I}+\mathrm{II}$ & $59[64]$ & $11[22]$ & \multirow[t]{2}{*}{$<0.0001^{\mathrm{e}}$} \\
\hline III+IV & $33[36]$ & $40[78]$ & \\
\hline
\end{tabular}

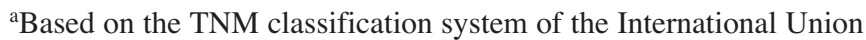
against Cancer (UICC). 'Well-SCC, well-differentiated SCC; modSCC, moderately-differentiated SCC; poor-SCC, poorly-differentiated SCC. ${ }^{\mathrm{c} S t u d e n t}$ 's t-test, ${ }^{\mathrm{d}}$ Kruskall Wallis and ${ }^{\mathrm{e}}$ Mann-Whitney U test.

Table III summarizes the relationship between the p-Akt expression and various clinicopathological parameters in the two groups of patients. In patients with ESCC who did not receive chemotherapy, p-Akt expression did not correlate with any clinicopathological parameters except for depth of tumor invasion. In those patients, T3/T4 tumors tended to show a weak expression of p-Akt, compared with T1/T2 tumors. In patients with ESCC who received chemotherapy, the p-Akt expression was not associated with any clinicopathological parameters, including lymph node status, depth of tumor invasion and differentiation of tumor. With regard to the clinical response to chemotherapy and p-Akt expression, a high percentage of non-responders had p-Akt-positive ESCC compared with responders, but the difference between the two groups was not statistically significant.

Kaplan-Meier survival curves were constructed using overall survival. Among the patients who did not receive chemotherapy, the survival of those with a high p-Aktexpressing ESCC was not different from that of patients with a low p-Akt-expressing ESCC (Fig. 2a). As with the p-Akt expression, the p-mTOR expression was not associated with patient survival in patients with ESCC who did not receive chemotherapy (data not shown). Among patients who received chemotherapy, however, those with a high p-Akt-expressing ESCC had significantly worse prognosis than patients with a low p-Akt-expressing ESCC (3-year survival, 67 vs. 23\%, $\mathrm{p}=0.0058)$ (Fig. 2b).

Changes in the p-Akt expression during chemotherapy and clinical outcome. In 37 out of 51 patients ESCC who received preoperative chemotherapy, we used immunohistochemistry to compare biopsy samples obtained before chemotherapy with the surgical specimens after chemotherapy. Among these patients, 9 showed an increased p-Akt expression after chemotherapy but none showed a reduction in the $\mathrm{p}$-Akt expression after chemotherapy, compared with the expression before chemotherapy (Table IV). Furthermore, the percentage of patients with a high p-Akt expression was significantly higher after chemotherapy versus before chemotherapy [19 $(51.4 \%)$ versus $10(27.0 \%)$ of 37$](\mathrm{p}=0.0348)$. The evaluation of the association between the changes in p-Akt expression during chemotherapy and clinical outcome, including the clinical response to chemotherapy and survival, showed a tendency for poor clinical response to chemotherapy in 19 patients with a low-to-high or high-to-high expression of p-Akt during chemotherapy, compared with 18 patients with a lowto-low expression of p-Akt (Table V). This former group of patients exhibited a significant trend towards poor survival, compared with the latter group ( $\mathrm{p}=0.0022)$ (Fig. 3).

Table II. Comparison of the p-Akt and p-mTOR expression between the ESCC of patients who did or did not receive preoperative chemotherapy.

\begin{tabular}{|c|c|c|c|c|c|c|c|}
\hline \multirow[t]{2}{*}{ Chemotherapy } & \multirow[b]{2}{*}{ Total number } & \multicolumn{3}{|c|}{ p-Akt expression } & \multicolumn{3}{|c|}{ p-mTOR expression } \\
\hline & & Low & High & p-value & Low & High & p-value \\
\hline Untreated [\%] & 92 & 69 [75] & $23[25]$ & & $44[48]$ & $48[52]$ & \\
\hline Treated [\%] & 51 & 25 [49] & $26[51]$ & $\mathrm{p}=0.0018$ & 30 [59] & $21[41]$ & $\mathrm{p}=0.2090$ \\
\hline
\end{tabular}

p-Akt, phosphorylated-Akt and p-mTOR, phosphorylated-mammalian target of rapamycin. Mann-Whitney U test. 
Table III. Correlation between the various clinicopathological parameters and p-Akt expression in surgical specimens of ESCC patients who did and did not receive chemotherapy.

\begin{tabular}{|c|c|c|c|c|c|c|}
\hline & \multicolumn{3}{|c|}{ p-Akt expression without chemotherapy } & \multicolumn{3}{|c|}{ p-Akt expression with chemotherapy } \\
\hline & Low $(\mathrm{n}=69)[\%]$ & High $(n=23)[\%]$ & p-value & Low $(\mathrm{n}=25)[\%]$ & High $(n=26)[\%]$ & p-value \\
\hline Age (mean \pm SEM) & $64 \pm 7.90$ & $64 \pm 7.48$ & & $61 \pm 6.9$ & $61 \pm 7.5$ & \\
\hline \multicolumn{7}{|l|}{ Gender } \\
\hline Male & $63[74]$ & $22[26]$ & $\mathrm{p}=0.498$ & $21[41]$ & $24[59]$ & $\mathrm{p}=0.3573$ \\
\hline Female & $6[86]$ & $1[24]$ & & $24[67]$ & $2[33]$ & \\
\hline \multicolumn{7}{|l|}{ Location of tumor } \\
\hline Upper thoracic & 7 [78] & $2[22]$ & $\mathrm{p}=0.6537$ & $3[33]$ & $4[67]$ & $\mathrm{p}=0.3376$ \\
\hline Middle thoracic & $34[72]$ & $13[28]$ & & $12[63]$ & 7 [37] & \\
\hline Lower thoracic & $28[77]$ & $8[23]$ & & $10[40]$ & $15[60]$ & \\
\hline \multicolumn{7}{|c|}{ Depth of tumor invasion ${ }^{\mathrm{a}}$} \\
\hline $\mathrm{cT} 1+2$ & $27[63]$ & $16[37]$ & $\mathrm{p}=0.0117$ & $10[62]$ & $6[38]$ & $\mathrm{p}=0.6866$ \\
\hline cT3+4 & $42[86]$ & 7 [14] & & $15[44]$ & $20[56]$ & \\
\hline \multicolumn{7}{|c|}{ Lymph node metastasis ${ }^{\mathrm{a}}$} \\
\hline cNO & 33 [79] & 9 [21] & $\mathrm{p}=0.4708$ & $2[67]$ & $1[33]$ & $\mathrm{p}=0.5326$ \\
\hline $\mathrm{cN} 1$ & $36[72]$ & $14[28]$ & & $23[48]$ & $25[52]$ & \\
\hline \multicolumn{7}{|l|}{ Differentiation } \\
\hline Well & $22[90]$ & $2[10]$ & $\mathrm{p}=0.0919$ & $6[46]$ & 7 [54] & $\mathrm{p}=0.9228$ \\
\hline Mod & $32[70]$ & $14[30]$ & & $10[48]$ & $11[52]$ & \\
\hline Poor & $15[68]$ & 7 [32] & & $9[53]$ & 8 [47] & \\
\hline \multicolumn{7}{|l|}{ cStage } \\
\hline Stage I+II & $43[73]$ & $16[27]$ & $\mathrm{p}=0.5326$ & 8 [72] & 4 [27] & $\mathrm{p}=0.0787$ \\
\hline Stage III+IV & 26 [79] & 7 [21] & & 17 [47] & $23[58]$ & \\
\hline \multicolumn{7}{|l|}{ Clinical response } \\
\hline bNC/PD & & & & 12 [39] & $19[61]$ & \\
\hline cPR & & & & $13[65]$ & $7[35]$ & $\mathrm{p}=0.0667$ \\
\hline
\end{tabular}

${ }^{a}$ Based on the TNM classification system of the International Union against Cancer. For abbreviations, see Tables I and II. ${ }^{b} \mathrm{NC}$, no change; PD, progressive disease and ${ }^{\mathrm{P} R}$, partial response. By Mann-Whitney $\mathrm{U}$ or Kruskall Wallis test as appropriate.
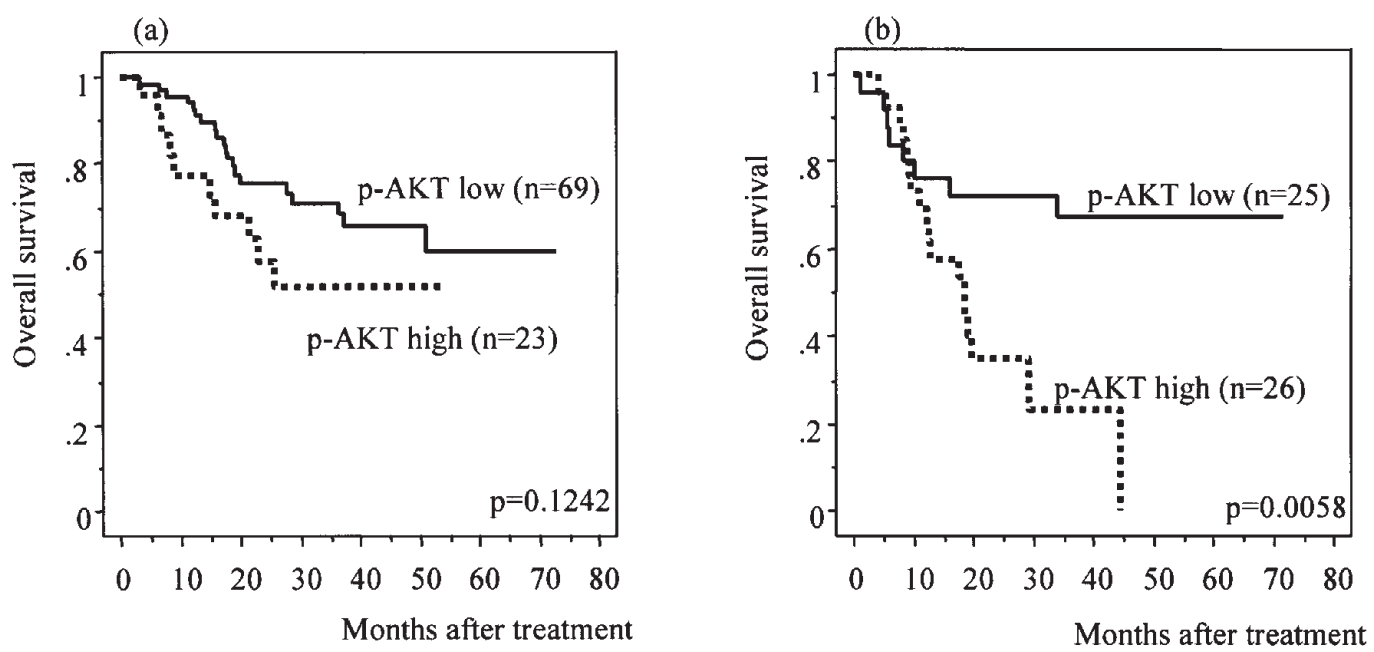

Figure 2. Overall survival by phosphorylated-Akt expression status for ESCC patients who did not receive (a) or received (b) preoperative chemotherapy. A significant difference was observed between the ESCC patients on preoperative chemotherapy with a low and those with a high p-Akt expression, but not with the ESCC patients who did not receive preoperative chemotherapy. 
Table IV. Changes in p-Akt expression during chemotherapy in 37 esophageal cancers of patients who received preoperative chemotherapy.

\begin{tabular}{llrrr}
\hline & & \multicolumn{3}{c}{ After chemotherapy } \\
\cline { 3 - 5 } & $\begin{array}{c}\text { p-AKT } \\
\text { expression }\end{array}$ & Low & High & Total \\
\hline Before chemotherapy & Low & 18 & 9 & 27 \\
& High & 0 & 10 & 10 \\
& Total & 18 & 19 & 37 \\
& & & & $\mathrm{p}=0.0348$ \\
\hline
\end{tabular}

For abbreviations, see Table II. Wilcoxon singled-rank test.

Table V. Relationship between changes in p-Akt expression during chemotherapy and clinical response.

\begin{tabular}{lrcc}
\hline & \multicolumn{3}{c}{ Clinical response } \\
\cline { 2 - 4 } & $\mathrm{PR}^{\mathrm{a}}$ & $\mathrm{NC} \mathrm{PD}^{\mathrm{b}}$ & Total \\
\hline Change of p-AKT expression & & & \\
Low $\rightarrow$ low & 10 & 8 & 18 \\
Low $\rightarrow$ high & 2 & 7 & 9 \\
High $\rightarrow$ high & 2 & 8 & 10 \\
Total & 14 & 23 & 37 \\
& & & $\mathrm{p}=0.0959$ \\
\hline
\end{tabular}

${ }^{a} \mathrm{PR}$, partial response; ${ }^{\mathrm{N} C}$, no change and $\mathrm{PD}$, progressive disease. Kruskall Wallis test.

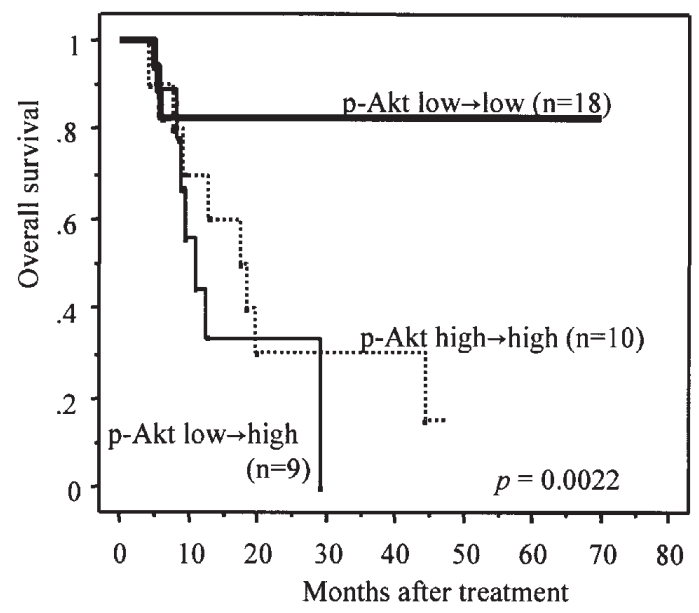

Figure 3. Overall survival by a change in the phosphorylated-Akt expression during chemotherapy for 37 ESCC patients who received preoperative chemotherapy. The survival of ESCC patients significantly differed with the change of the p-Akt expression during chemotherapy.

Univariate and multivariate analyses of the prognostic factors in 51 ESCC patients who received preoperative chemotherapy.
A univariate analysis of 51 patients who received preoperative chemotherapy identified a deeper invasion of tumor and high p-Akt expression, but not lymph node metastasis or histopathological response, to correlate significantly with poor prognosis (Table VI). The clinical response showed a borderline significance for predicting survival. A multivariate analysis using the three parameters of tumor depth of invasion, clinical response and p-Akt expression, identified p-Akt expression as the only independent and significant determinant of prognosis for patients with ESCC who received preoperative chemotherapy.

\section{Discussion}

In the present study, we used immunohistochemistry to evaluate the clinical significance of the activation of the AktmTOR pathway in patients with ESCC who did or did not receive chemotherapy preoperatively and found that preoperative chemotherapy activated Akt in this tumor. In addition, we found that a high p-Akt expression was significantly associated with poor prognosis of patients with ESCC even when they received preoperative chemotherapy. Thus, our study demonstrates the chemotherapy-induced activation of Akt in vivo and its inverse correlation with poor patient survival.

The role of $\mathrm{p}$-Akt expression has been investigated recently in various types of cancer patients, and some studies have documented the correlation between Akt activation and tumor invasion, and poor prognosis in solid tumors, such as breast, head and neck and pancreatic cancers $(8,27,28)$. Our data, however, showed that the activation of Akt was not associated with tumor progression and did not affect the survival of ESCC patients who did not receive chemotherapy. In untreated ESCC, the activation of Akt was more often observed in T1/ T2 tumors than T3/T4 tumors. This result suggests that Akt activation may be a frequent and early event in tumorigenesis though it is not involved in tumor aggressiveness in untreated ESCC.

Akt activation plays an important role in protecting cells from undergoing apoptosis. Recent in vitro studies demonstrated that certain chemotherapeutic agents, such as cisplatin and doxorubicin activate Akt in cancer cells by phosphorylation and attenuate chemotherapy-induced apoptosis $(9,20)$. Similarly, Akt is phosphorylated and activated by ionizing radiation and its activation confers radioresistance (29). The inhibition of Akt activation using PI3K inhibitors, such as wortmannin and LY294002, reversed chemoresistance and radioresistance in cancer cells $(20,29)$. In our study, a comparison of the p-Akt expression before and after chemotherapy demonstrated that patients with ESCC who show an increased p-Akt expression during chemotherapy tended to have a poor response to chemotherapy, although this tendency was not statistically significant. Moreover, p-Akt overexpression was closely associated with poor prognosis in patients with ESCC who received chemotherapy preoperatively. These results suggest that an inducible activation of p-Akt in the ESCC of patients who received chemotherapy plays an important role in anti-apoptosis and is related to drug resistance and poor survival. Taken together, these results suggest that the combination of Akt signal inhibitors 
Table VI. The univariate and multivariate analyses of the clinicopathological factors for overall survival in 51 patients with esophageal cancer who received preoperative chemotherapy.

\begin{tabular}{|c|c|c|c|c|c|}
\hline \multirow[b]{2}{*}{ Variable [cases] } & \multicolumn{2}{|c|}{ Univariate analysis } & \multicolumn{3}{|c|}{ Multivariate analysis } \\
\hline & Relative risk & $\mathrm{p}$-value & Relative risk & $95 \% \mathrm{CI}^{\mathrm{a}}$ & p-value \\
\hline \multicolumn{6}{|l|}{ p-Akt expression } \\
\hline \multicolumn{6}{|l|}{ Low [25] } \\
\hline High [26] & 3.185 & 0.0101 & 2.667 & $1.061-6.707$ & 0.0370 \\
\hline \multicolumn{6}{|c|}{ Depth of tumor invasion } \\
\hline \multicolumn{6}{|c|}{$\mathrm{T} 1 / \mathrm{T} 2[16]$} \\
\hline T3/T4 [35] & 2.573 & 0.0435 & 1.583 & $0.533-4.706$ & 0.4083 \\
\hline \multicolumn{6}{|l|}{ Clinical response } \\
\hline \multicolumn{6}{|l|}{ PR [20] } \\
\hline $\mathrm{NC} / \mathrm{PD}[31]$ & 2.350 & 0.0543 & 1.789 & $0.650-4.927$ & 0.2603 \\
\hline \multicolumn{6}{|l|}{ Lymph node status } \\
\hline \multicolumn{6}{|l|}{ pN0 [14] } \\
\hline pN1 [37] & 2.506 & 0.0928 & N.D. ${ }^{b}$ & & \\
\hline \multicolumn{6}{|c|}{ Tumor differentiation } \\
\hline \multicolumn{6}{|c|}{ Well /mod SCC [34] } \\
\hline Poor SCC [17] & 1.534 & 0.2814 & N.D. & & \\
\hline \multicolumn{6}{|c|}{ Tumor location } \\
\hline \multicolumn{6}{|c|}{ Upper/middle [26] } \\
\hline Lower [25] & 1.331 & 0.4670 & N.D. & & \\
\hline \multicolumn{6}{|c|}{ Histological response } \\
\hline \multicolumn{6}{|c|}{ Grade 1b-2 [15] } \\
\hline Grade 0-1a [36] & 1.129 & 0.7760 & N.D. & & \\
\hline
\end{tabular}

For abbreviations, see Tables I, II and III. ${ }^{\mathrm{a} C I}$, confidence interval and ${ }^{\mathrm{b}} \mathrm{N} . \mathrm{D}$., not done.

and chemotherapy may be a viable strategy in patients with ESCC.

The activation of Akt after chemotherapy in ESCC can be involved not only in the anti-apoptotic function but also in the stimulation of glycolysis. Warburg (30) indicated that cancer cells preferentially utilize glycolytic pathways for energy generation while down-regulating their aerobic respiratory activity. Although this metabolic shift toward glycolysis has been noted as characteristic of many types of cancer cells, its mechanism remains to be elucidated. Studies recently demonstrated that the activation of Akt is sufficient to stimulate the switch to glycolysis characteristic of cancer cells (31). Akt activation stimulates the transcription of glucose transporter genes and translocation to the plasma membrane of glucose transporters, and also activates 6-phosphoflucto-2kinase, a positive regulator of glucose metabolism (32). This metabolic switch induced by Akt activation renders cancer cells less dependent on an oxygen supply, and may allow them to survive in more a hypoxic environment, such as an environment after radiation therapy or chemotherapy. Genotoxic exposure including chemotherapeutic drugs and ionizing radiation is associated with a reduced glucose uptake and glycolytic metabolism and changes in glucose metabolism after genotoxic damage result in mitochondrial damage, leading to apoptosis (33). The activation of p-Akt after chemotherapy may be involved in drug resistance, by inhibition of this decrease in glycolytic metabolism leading to apoptosis. Thus, another reason for the high correlation between p-Akt expression and poor prognosis of patients with ESCC who received chemotherapy may be that the chemotherapy-induced activation of p-Akt confers a survival advantage on cancer cells by stimulating glycolysis.

mTOR is a downstream mediator in the PI3K-Akt signaling pathway, and has been recognized as a potential therapeutic target for the treatment of cancer. Studies recently reported frequent mTOR phosphorylation and its significant association with Akt phosphorylation in solid tumors, such as ovarian and non-small cell lung cancer $(20,34)$. In the present study, we investigated whether the activation of mTOR parallels that of Akt by immunohistochemistry using an antibody directed at the phosphorylated mTOR Ser 2448. However, contrary to our expectations, we found that mTOR phosphorylation did not correlate with Akt phosphorylation in ESCC without and in ESCC with chemotherapy (data not shown). One possible explanation for this disaccord is that mTOR is directly influenced by other stimuli, such as nutrient 
starvation and hypoxia, downstream of Akt in ESCC. mTOR is a major regulator of cellular energy and is constitutively activated in the presence of growth factors and hormones such as insulin and nutrients. mTOR is also regulated by hypoxia and by the ATP level (35). It was demonstrated that mTOR and its downstream molecules such as 4E-BP1, p70S6K and eIF4G are down-regulated when cancer cells are exposed to hypoxia (36) and that suppression of the mTOR pathway rescued cancer cells from hypoxia-induced necrotic cell death under hypoxic conditions (37). These findings suggest that the down-regulation of mTOR activity by hypoxia is a cellular energy conservation strategy in cancer cells and favorable for the survival of cancer cells under hypoxic stress. Thus, hypoxic conditions may affect the mTOR function in ESCC.

The mechanisms by which Akt activation disables apoptosis and contributes to clinical drug resistance are unclear. However, recent studies demonstrated that the inhibition of mTOR using rapamycin or its analogue reverses the chemoresistance induced by Akt activation in lymphoma and breast cancer cells, suggesting that Akt-induced chemoresistance is mediated in part by signaling through the mTOR pathway $(38,39)$. On the other hand, another study showed that mTOR inhibitors suppressed the phosphorylation of the p70S6 kinase and 4E-BP1 downstream of mTOR signaling, but concurrently and paradoxically increased Akt activation (40). It was also demonstrated that mTOR inhibition induced the expression of insulin receptor substrate-1 (IRS-1) and the activation of Akt (41). Thus, mTOR functions downstream of Akt signaling and the effect of mTOR inhibition in cancer cells is complex, requiring further investigation in human cancers including ESCC.

In conclusion, our results showed that Akt activation is significantly increased during chemotherapy in patients with ESCC who receive preoperative chemotherapy, resulting in a clinically poor response to chemotherapy and poor survival. Our findings suggest that the combination of Akt signaling inhibition and chemotherapy may prove to be a successful strategy against ESCC for improving survival.

\section{References}

1. Muller JM, Erasmi H, Stelzner M, Zieren U and Pichlmaier H: Surgical therapy of oesophageal carcinoma. Br J Surg 77: 845-857, 1990.

2. Urschel JD, Vasan $\mathrm{H}$ and Blewett CJ: A meta-analysis of randomized controlled trials that compared neoadjuvant chemotherapy and surgery to surgery alone for respectable esophageal cancer. Am J Surg 183: 274-279, 2002.

3. Franke TF, Kaplan DR and Cantley LC: PI3K: Downstream Akt blocks apoptosis. Cell 88: 435-437, 1997.

4. Murthy SS, Tosolini A, Taguchi T and Testa JR: Mapping of AKT3, encoding a member of the Akt/protein kinase B family, to human and rodent chromosomes by fluorescence in situ hybridization. Cytogenet Cell Genet 88: 38-40, 2000.

5. Testa JR and Bellacosa A: AKT plays a central role in tumorigenesis. Proc Natl Acad Sci USA 98: 10983-10985, 2001.

6. Nakatani K, Thompson DA, Barthel A, Sakaue H, Liu W, Weigel RJ and Roth RA: Up-regulation of Akt3 in estrogen receptor-deficient breast cancers and androgen-independent prostate cancer lines. J Biol Chem 274: 21528-21532, 1999.

7. Sun M, Wang G, Paciga JE, Feldman RI, Yuan ZQ, Ma XL, Shelley SA, Jove R, Tsichlis PN, Nicosia SV and Cheng JQ: $\mathrm{AKT} 1 / \mathrm{PKB} \alpha$ kinase is frequently elevated in human cancers and its constitutive activation is required for oncogenic transformation in NIH3T3 cells. Am J Pathol 159: 431-437, 2001.
8. Yamamoto S, Tomita Y, Hoshida Y, Morooka T, Nagano H, Dono K, Umeshita K, Sakon M, Ishikawa O, Ohigashi H, Nakamori S, Monden M and Aozasa K: Prognostic significance of activated Akt expression in pancreatic adenocarcinoma. Clin Cancer Res 10: 2846-2850, 2004.

9. Yang X, Fraser M, Moll UM, Basak A and Tsang BK: Aktmediated cisplatin resistance in ovarian cancer: Modulation of p53 action on caspase-dependent mitochondrial death pathway. Cancer Res 66: 3126-3136, 2006.

10. Yuan ZQ, Sun M, Feldman RI, Wang G, Ma X, Jiang C, Coppola D, Nicosia SV and Cheng JQ: Frequent activation of AKT2 and induction of apoptosis by inhibition of phosphoinositide-3-OH kinase/Akt pathway in human ovarian cancer. Oncogene 19: 2324-2330, 2000.

11. Datta SR, Brunet A and Greenberg ME: Cellular survival: a play in three Akts. Genes Dev 13: 2905-2927, 1999.

12. Brunet A, Bonni A, Zigmond MJ, Lin MZ, Juo P, Hu LS, Anderson MJ, Arden KC, Blenis J and Greenberg ME: Akt promotes cell survival by phosphorylating and inhibiting forkhead transcription factor. Cell 96: 857-868, 1999.

13. Datta SR, Dudek H, Tao X, Masters S, Fu H, Gotoh Y and Greenberg ME: Akt phosphorylation of BAD couples survival signals to the cell-intrinsic death machinery. Cell 97: 231-241, 1997.

14. Ozes ON, Mayo LD, Gustin JA, Pfeffer SR, Pfeffer LM and Donner DB: NF- $\mathrm{KB}$ activation by tumor necrosis factor requires the Akt serine-threonine kinase. Nature 401: 82-85, 1999.

15. Romanshkova JA and Makarow SS: NF- $\mathrm{KB}$ is a target of Akt in anti-apoptotic PDBF signaling. Nature 401: 86-90, 1999.

16. von Manteuffel SR, Dennis PB, Pullen N, Gingras AC, Sonenberg $\mathrm{N}$ and Thomas $\mathrm{G}$ : The insulin-induced signaling pathway leading to S6 and initiation factor 4Ebinding protein1 phosphorylation bifurcates at rapamycin-sensitive point immediately upstream of p70S6K. Mol Cell Biol 17: 5426-5436, 1997.

17. Hay N and Sonenberg N: Upstream and downstream of mTOR. Genes Dev 18: 1926-1945, 2004.

18. Amornphimoltham P, Patel V, Sodhi A, Nikitakis NG, Sauk JJ, Sausville EA, Molinolo AA and Gutkind JS: Mammalian target of rapamycin, a molecular target in squamous cell carcinomas of the head and neck. Cancer Res 65: 9953-9961, 2005.

19. Martin ME, Pérez I, Redondo C, Álvarez I, Salinas M and Fando JL: 4E binding protein 1 expression is inversely correlated to the progression of gastrointestinal cancers. Int J Biochem Cell Biol 32: 633-642, 2000.

20. Altomare DA, Wang HQ, Skele KL, Rienzo AD, Klein-Szanto, Godwin AK and Testa JR: AKT and mTOR phosphorylation is frequently detected in ovarian cancer and can be targeted to disrupt ovarian tumor cell growth. Oncogene 23: 5853-5857, 2004.

21. Joshi MB, Shirota Y, Danenberg KD, Conlon DH, Salonga DS, Herndon JE II, Danenberg PV and Harpole DH Jr: High expression of TS1, GSTP1 and ERCC1 are risk factors for survival in patients with trimodality therapy for esophageal cancer. Clin Cancer Res 11: 2215-2221, 2005.

22. Kishi K, Doki Y, Yano M, Yasuda T, Fujiwara Y, Takiguchi S, Kim S, Higuchi I and Monden M: Reduced MLH1 expression after chemotherapy is an indicator for poor prognosis in esophageal cancers. Clin Cancer Res 9: 4368-4375, 2003.

23. Nooter K, Kok T, Bosman FT, van Wingerden KE and Stoter G: Expression of the multidrug resistance protein (MRP) in squamous cell carcinoma of the oesophagus and response to preoperative chemotherapy. Eur J Cancer 34: 81-86, 1998.

24. Therasse P, Arbuck S, Eisenhauer EA, Wanders J, Kaplan RS, Rubinstein L, Verweij J, van Glabbeke M, van Oosterom AT, Christian MC and Gwyther SG: New guidelines to evaluate the response to treatment in solid tumors. European Organization for Research and Treatment of Cancer, National Cancer Institute of the United States, National Cancer Institute of Canada. J Natl Cancer Inst 92: 205-216, 2000.

25. Japanese Society for Esophageal Diseases. In: Guidelines for the Clinical and Pathologic Studies on Carcinoma of the Esophagus. (ed). 9th edition Kanehara Syuppan, Tokyo, 1999.

26. Miyata H, Doki Y, Shiozaki H, Inoue M, Yano M, Fujiwara Y, Yamamoto H, Nishioka K, Kishi K and Monden M: CDC25B and p53 are independently implicated in radiation sensitivity for human esophageal cancers. Clin Cancer Res 6: 4859-4865, 2000.

27. Schmitz KJ, Otterbach F, Callies R, Levkau B, Hölscher M, Hoffmann O, Grabellus F, Kimmig R, Schmid KW and Baba HA: Prognostic relevance of activated Akt kinase in node-negative breast cancer: A clinicopathological study of 99 cases. Mod Pathol 17: 15-21, 2004. 
28. Massarelli E, Liu DD, Lee JJ, El-Naggar AK, Lo Muzio L, Staibano S, De Placido S, Myers JN and Papadimitrakopoulou VA: Akt activation correlates with adverse outcome in tongue cancer. Cancer 104: 2430-2436, 2005.

29. Rosenzweig KE, Youmell MB, Palayoor ST and Price BD: Radiosensitization of human tumor cells by the phosphatidylinositol 3-kinase inhibitors wortmannin and LY294002 correlates with inhibition of DNA-dependent protein kinase and prolonged G2-M delay. Clin Cancer Res 61: 3986-3997, 2001.

30. Warburg O: On the origin of cancer cells. Science 123: 309-314, 1956.

31. Elstrom RL, Bauer DE, Buzzai M, Karnauskas R, Harris MH, Plas DR, Zhuang H, Cinalli RM, Alavi A, Rudin CM and Thompson CB: Akt stimulates aerobic glycolysis in cancer cells. Cancer Res 64: 3892-3899, 2004.

32. Edinger AL and Thompson CB: Akt maintains cell size and survival by increasing mTOR-dependent nutrient uptake. Mol Biol Cell 13: 2276-2288, 2002.

33. Zhou R, Vander Heiden MG and Rudin CM: Genotoxic exposure is associated with alterations in glucose uptake and metabolism. Cancer Res 62: 3515-3520, 2002.

34. Balsara BR, Pei J, Mitsuuchi Y, Page R, Klein-Szanto A, Wang $\mathrm{H}$, Unger $\mathrm{M}$ and Testa JR: Frequent activation of AKT in non-small cell lung carcinomas and preneoplastic bronchial lesions. Carcinogenesis 25: 2053-2059, 2004.

35. Proud CG: The multifaceted role of $\mathrm{mTOR}$ in cellular stress responses. DNA Repair 3: 927-934, 2004.
36. Arsham AM, Howell JJ and Simon MC: A novel hypoxia inducible factor-independent hypoxic response regulating mammalian target of rapamycin and its targets. J Biol Chem 278: 29655-29660, 2003.

37. Hamanaka Y, Mukai M, Shimamura M, Kitagawa T, Nishida T, Isohashi $\mathrm{F}$, Ito $\mathrm{T}$, Nishizawa $\mathrm{Y}$, Tatsuta $\mathrm{M}$, Matsuda $\mathrm{H}$ and Inoue M: Suppression of PI3K/mTOR pathway rescues LLC cells from cell death by hypoxia. Biochem Biophys Res Commun 330: 318-326, 2005.

38. Wendel HG, de Stanchina E, Fridman JS, Malina A, Ray S, Kogan S, Cordon-Cardo C, Pelletier J and Lowe SW: Survival signaling by Akt and eIF-4E in oncogenesis and cancer therapy. Nature 428: 332-327, 2004

39. de Graffenried LA, Friedrichs WE, Russell DH, Donzis EJ, Middleton AK, Silva JM, Roth RA and Hidalgo M: Inhibition of mTOR activity restores tamoxifen response in breast cancer cells with aberrant Akt activity. Clin Cancer Res 10: 8059-8067, 2004.

40. Sun SY, Rosenberg LM, Wang X, Zhou Z, Yue P, Fu H and Khuri FR: Activation of Akt and eIF4E survival pathways by rapamycin-mediated mammalian target of rapamycin inhibition. Cancer Res 65: 7052-7058, 2005.

41. O'Reilly KE, Rojo F, She QB, Solit D, Mills GB, Smith D, Lane H, Hofmann F, Hicklin DJ, Ludwig DL, Baselga J and Rosen N: mTOR inhibition induces upstream receptor tyrosine kinase signaling and activates Akt. Cancer Res 66: 1500-1508, 2006. 